Erratum

\title{
Erratum to: Rho Kinase Regulation of Fibroblast Migratory Mechanics in Fibrillar Collagen Matrices
}

\author{
Chengxin Zhou ${ }^{1,2}$ and W. Matthew Petroll ${ }^{1,2}$ \\ ${ }^{1}$ Biomedical Engineering Graduate Program, University of Texas Southwestern Medical Center, Dallas, TX, USA; and \\ ${ }^{2}$ Department of Ophthalmology, University of Texas Southwestern Medical Center, 5323 Harry Hines Blvd., Dallas, \\ TX 75390-9057, USA
}

\section{Erratum to: Cellular and Molecular Bioengineering DOI 10.1007/s12195-010-0106-2}

The acknowledgments were left out of the original publication of this article. They appear here in their entirety.

\section{ACKNOWLEDGMENTS}

This study was supported in part by NIH R01 EY 013322, NIH R24 EY016664, and an unrestricted grant and Senior Scientific Investigator Award (WMP) from Research to Prevent Blindness, Inc., NY, NY.

Address correspondence to W. Matthew Petroll, Department of Ophthalmology, University of Texas Southwestern Medical Center, 5323 Harry Hines Blvd., Dallas, TX 75390-9057, USA. Electronic mail: matthew.petroll@utsouthwestern.edu

The online version of the original article can be found under doi: 10.1007/s12195-010-0106-2. 